\title{
Faktor Yang Berkaitan Dengan Keikutsertaan Lansia Dalam Kegiatan Posbindu Di Puskesmas Nusaherang Kabupaten Kuningan
}

\section{Relating Factors to the Participation of Elderly in Posbindu Activities in Nusaherang Public Health Center Kuningan Regency}

\section{Andy Muharry ${ }^{1}$, Fitri Kurnia Rahim ${ }^{2}$, Syifa Fadilah $^{3}$}

\author{
${ }^{1}$ Program Studi Kesehatan Masyarakat, Universitas Siliwangi, Tasikmalaya \\ e-mail: *11 Andy.muharry@unsil.ac.id, ${ }^{2}$ fikura.zone@gmail.com, ${ }^{3}$ Syifa@gmail.com
}

\begin{abstract}
Abstrak
Pusdatin Kemenkes RI memperkirakan jumlah lansia pada tahun 2050 mencapai 21,4\%. Meningkatnya jumlah penduduk lansia memiliki sisi negatif yang perlu diwaspadai seperti munculnya hipertensi. Hipertensi merupakan penyakit yang sering ditemukan pada lansia. Prevalensi hipertensi di Jawa Barat pada tahun 2015 sebesar 31,56\% meningkat menjadi sebesar 32,59\% pada tahun 2016. Kecamatan Nusaherang merupakan salah satu kecamatan di Kabupaten Kuningan yang masih ditemukan kasus hipertensi pada lansia. Posbindu merupakan upaya yang dilakukan untuk deteksi dini dan pencegahan hipertensi pada lansia. Namun tidak semua masyarakat dapat berpartisipasi dalam kegiatan tersebut. Tujuan penelitian menganalisis faktor-faktor yang berkaitan dengan keikutsertaan lansia dalam program Posbindu. Penelitian ini merupakan survei analitik dengan rancangan studi cross sectional. Populasi dalam penelitian ini adalah lansia yang berada di wilayah kerja Puskesmas Nusaherang sebanyak 186 orang. Jumlah sampel sebanyak 63 dipilih secara random dari populasi. Instrumen yang digunakan berupa kuesioner. Analisis data menggunakan analaisis univariat, bivariat dan multivariat. Variabel yang berhubungan dengan keikutsertaan lansia dalam posbindu yaitu pekerjaan, pengetahuan, jenis kelamin dan dukungan keluarga. Variabel yang paling berpengaruh terhadap keikutsertaan lansia dalam posbindu adalah jenis kelamin. Berdasarkan hasil penelitian disarankan keluarga atapun masyarakat dan kader kesehatan dapat lebih memotivasi lansia untuk berkunjung ke posbindu khususnya lansia yang berjenis kelamin laki-laki.
\end{abstract}

Kata kunci: Keikutsertaan, lansia, posbindu

\begin{abstract}
The Indonesian Ministry of Health's estimates that the number of elderly in 2050 will reach $21.4 \%$. The increasing number of the elderly population has a negative side that needs to be watched out for such as the emergence of hypertension. Hypertension is a disease that is often found in the elderly. The prevalence of hypertension in West Java in 2015 amounted to 31.56\%, increasing to $32.59 \%$ in 2016. Nusaherang Subdistrict is one of the sub-districts in Kuningan Regency which is still found cases of hypertension in the elderly. Posbindu is an effort made for early detection and prevention of hypertension in the elderly. But not all ederly can participate in these activities. The purpose of this research was to identify the factors related to the participation of the elderly in the Posbindu. This research used cross-sectional study design. The population in this study is the elderly who are in the Nusaherang Public Health Centers. The samples were taken using simple random sampling technique, the subject consisted of 63 people. The data were collected using questionnaires. Data were analyzed using chi-square test and conditional logistic regression. The variables which had significant related with the participation of the elderly in posbindu were work, knowledge, gender and family support. The variable that most influences the elderly participation in postbindu is gender. Based on the results of the study it is suggested that families or the community and health volunteer can further motivate the elderly to visit posbindu, especially the elderly who are male.
\end{abstract}

Keywords: Participation, elderly, posbindu
DOI :https://doi.org/10.31943/afiasi.v5i1.97

\section{Pendahuluan}

Masalah penyakit tidak menular (PTM) hingga saat ini masih menjadi penyebab utama kematian di berbagai negara. Dari 57 juta kasus kematian sebanyak dua pertiganya disebabkan oleh 
PTM. Masalah PTM pada umumnya berkaitan dengan kondisi umur seseorang yang sudah menua. Namun tidak menutup kemungkinan masalah PTM dapat terjadi pada kelompok umur yang lebih muda. Menurut WHO, kematian akibat PTM diperkirkan akan terus mengalami peningkatan di seluruh dunia khususnya di negara-negara dengan kondisi perekonomian yang masih rendah. Diperkirakan lebih dari 2/3 dari populasi di dunia meninggal akibat PTM seperti stroke, penyakit jantung, kanker dan diabetes. ${ }^{1}$

Di Indonesia, diperkirakan jumlah penduduk lanjut usia terus mengalami peningkatan pada setiap tahunnya. Menurut Undang-undang Republik Indonesia No. 13 tahun 1998 tentang kesejahteraan Lanjut Usia, disebutkan bahwa yang dimaksud lanjut usia adalah seseorang yang telah mencapai usia 60 tahun ke atas. Hasil Susenas tahun 2016, jumlah lanjut usia di Indonesia sebanyak 8,69\% dari jumlah penduduk. ${ }^{2}$ Sementara menurut Pusdatin Kemenkes RI, jumlah lanjut usia pada tahun 2050 diperkirakan mencapai 21,4\%. Keberhasilan pembangunan di bidang kesehatan telah memberikan dampak diberbagai bidang, salah satunya adalah peningkatkan usia harapan hidup masyarakat Indonesia. Kondisi seperti ini tentunya perlu diwaspadai karena peningkatan usia harapan hidup memiliki dampak negatif seperti peningkatan angka beban tanggungan kelompok usia produktif dan beban penyakit tidak menular seperti hipertensi. ${ }^{3}$

Jumlah penderita hipertensi di Indonesia cenderung mengalami peningkatan. Berdasarkan hasil Survei Kesehatan Rumah Tangga pada tahun 2001, jumlah penduduk Indonesia yang mengalami hipertensi sebesar 8,3\% dan meningkat menjadi 27,5\% pada tahun 2004 . Hasil Riset Kesehatan dasar tahun 2013 menujukkan PTM yang banyak diderita oleh lansia yaitu hipertensi, arthritis dan stroke. ${ }^{4}$ Di Jawa Barat, prevalensi hipertensi pada tahun 2015 sebesar 31,56\% dan meningkat menjadi $32,59 \%$ pada tahun $2016 .{ }^{5}$ Jumlah penderita hipertensi pada lansia di wilayah kerja UPTD Puskesmas Nusaherang Kabupaten Kuningan menjadi masalah terbesar setelah penyakit dyspepsia.

Proses bertambahnya umur pada seseorang merupakan kondisi alamiah dimana fungsi fisiologis manusia pada fase ini mengalami penurunan sehingga mudah terkena penyakit. Selain itu bertambahnya umur seseorang mengakibatkan elastisitas pembuluh darah semakin berkurang. ${ }^{6}$ Beberapa faktor risiko yang memperbesar peluang seseorang terkena hipertensi diantaranya yaitu faktor lingkungan, genetik dan perilaku. Hasil studi yang dilakukan oleh Anggara dan Prayitno, menyebutkan bahwa faktor risko yang berkaitan dengan hipertensi diantaranya yaitu: pendidikan, umur, pekerjaan, kebiasaan merokok, indeks masa tubuh, kebiasaan minum alkohol, dan kurang olahraga. Hipertensi pada lansia dapat menyebabkan menurunnya kualitas hidup seseorang yang pada akhirnya menimbulkan kesulitan dalam interaksi sosial di masyarakat serta dapat meningkatkan angka kesakitan dan kematian akibat komplikasi-komplikasi yang ditimbulkan. ${ }^{7}$

Berbagai macam upaya sudah dilakukan oleh pemerintah dan masyarakat untuk mencegah meningkatknya kejadian hipertensi di Indonesia. Salah satunya dengan adanya Pos Pembinaan Terpadu (Posbindu). Posbindu adalah kegiatan yang dilakukan untuk memantau dan mendeteksi dini faktor resiko PTM, gangguan akibat kecelakaan dan tindakan kekerasan dalam rumah tangga secara terintegrasi yang dikelola oleh masyarakat melalui pembinaan terpadu. Posbindu merupakan wujud partisipasi masyarakat yang lebih menekankan pada upaya pencegahan untuk deteksi dini dan pengendalian keberadaan faktor resiko PTM secara terpadu. ${ }^{8}$

Dibutuhkan peran serta masyarkat dalam program tersebut, partisipasi masyarakat khususnya mereka yang memiliki risiko PTM sangat penting demi keberhasilan upaya pencegahan munculnya kejadian PTM, akan tetapi tidak semua orang memiliki kesadaran dalam hal tersebut. Berbagai faktor diduga memiliki peran penting yang berhubungan dengan keikutsertaan masyarakat khususnya lansia dalam kegiatan Posbindu. Studi yang dilakukan oleh Manihuruk tentang faktor- 
faktor yang berhubungan dengan kunjungan lansia ke Posbindu di Puskesmas Keluarahan Bintara Kota Bekasi menyebutkan bahwa pengetahuan, dukungan petugas kesehatan dan faktor kebutuhan merupakan faktor yang berhubungan dengan kunjungan lansia ke Posbindu. ${ }^{9}$ Selain itu dukungan keluarga dan dukungan tokoh masyarakat juga merupakan faktor penting yang mendorong masyarakat untuk aktif dalam kegiatan Posbindu. ${ }^{10}$

Keaktifan lansia dalam Posbindu dapat memberikan manfaat yang besar bagi kondisi kesehatannya. Adapun manfaat yang diperoleh lansia jika aktif dalam kegiatan Posbindu yaitu: kondisi kesehatannya akan selalu dimonitoring secara rutin, lansia mendapatkan konseling terkait dengan faktor risiko PTM dan melakukan aktifitas fisik bersama untuk meningkatkan kebugaran tubuh. ${ }^{8}$

Studi pendahuluan yang peneliti lakukan melalui data sekunder, diperoleh tingkat keikutsertaan lansia dalam program Posbindu di wilayah kerja Puskesmas Nusaherang diperoleh informasi bahwa lebih dari setengahnya (60\%) tingkat partsipiasi lansia termasuk dalam kategori sering, sebesar $27 \%$ termasuk dalam kategori kadang-kadang dan sebesar $13 \%$ termasuk dalam kategori tidak pernah datang ke Posbindu.

Rendahnya keikutsertaan lansia dalam Posbindu dapat menimbulkan masalah yang serius baik bagi lansia itu sendiri mapun bagi keluarganya. Kondisi kesehatan yang tidak termonitor dan faktor risiko PTM yang tidak terdeteksi secara langsung dapat meningkatkan angka kesakitan bahkan berujung pada kematian. Sedangkan kondisi kesehatan yang buruk pada lansia, sering sakitsakitan dapat menjadi beban bagi anggota keluarga. Penelitian ini dilakukan untuk mengetahui faktor yang berkaitan dengan keikutsertaan lansia dalam kegiatan Posbindu

\section{Metode Penelitian}

Peneitian ini menggunakan studi observasional dengan pendekatan cross sectional, dilakukan pada bulan Februari sd Juli 2017 di Puskesmas Nusaherang Kabupaten Kuningan. Populasi dalam penelitian ini adalah lansia. Jumlah sampel berjumlah 63 orang diambil secara simpel random sampling. Instrumen dalam penelitian ini berupa daftar pertanyaan yang digunakan untuk mengukur pekerjaan, pengetahuan, jenis kelamin, dukungan keluarga dan keikutsertaan lansia. Pengambilan data dilakukan dengan melakukan wawancara langsung kepada responden. Data dianalisis menggunakan program komputer. Analisis univariat bertujuan untuk mendeskripsikan variabel pekerjaan, pengetahuan, jenis kelamin, dukungan keluarga dan keikutsertaan lansia. Hasil analisis univariat disajikan dalam bentuk tabel distribusi frekuensi dan narasi. Analisis bivariat bertujuan untuk mengidentifikasi hubungan antara variabel bebas dengan variabel terikat. Analisis bivariat menggunakan uji chi square dengan nilai kemaknaan $\mathrm{p}<0,05$ dan untuk melihat variabel yang paling dominan menggunakan regresi logistik dengan tingkat kemaknaan p<0,05 dengan Confidence Interval (CI) 95\%. Nilai OR digunakan untuk melihat kekuatan hubungan antar variabel. 


\section{Hasil}

Jumlah sampel yang berhasil dikumpulkan dalam penelitian ini yaitu sebanyak 63 orang. Rata-rata usia responden 62,49 tahun, responden dengan umur paling muda yaitu 60 tahun dan responden dengan umur paling tua yaitu 68 tahun. Adapun karakteristik responden berdasarkan pekerjaan, jenis kelamin, dukungan keluarga dan keikutsertaan dalam program posbindu dapat dilihat pada tabel berikut ini:

Tabel 1. Karakteristik Responden BerdasarkanPekerjaan, Jenis Kelamin, Dukungan Keluarga dan Keikutsertaan Dalam Program Posbindu

\begin{tabular}{|c|c|c|c|}
\hline No & Variabel & $\mathbf{f}$ & $\%$ \\
\hline \multirow[t]{3}{*}{1} & Pekerjaan & & \\
\hline & - Bekerja & 29 & 46 \\
\hline & - Tidak bekerja & 34 & 54 \\
\hline \multirow[t]{3}{*}{2} & Pengetahuan & & \\
\hline & - Baik & 33 & 52,4 \\
\hline & - Cukup & 30 & 47,6 \\
\hline \multirow[t]{3}{*}{3} & Jenis Kelamin & & \\
\hline & - Perempuan & 32 & 58,8 \\
\hline & - Laki-laki & 32 & 49,2 \\
\hline \multirow[t]{3}{*}{3} & Dukungan Keluarga & & \\
\hline & - Baik & 42 & 66,7 \\
\hline & - Cukup & 21 & 33,3 \\
\hline \multirow[t]{3}{*}{4} & Keikutsertaan lansia & & \\
\hline & - $\quad$ Sering & 26 & 41,3 \\
\hline & - Kadang-kadang & 37 & 58,7 \\
\hline
\end{tabular}

Berdasarkan tabel 1. dapat diketahui bahwa sebesar 54\% responden tidak bekerja, sebesar 58,8\% respoden berjenis kelamin laki-laki, sebesar $66,7 \%$ responden mendapatkan dukungan baik dari keluarga dan sebesar 58,7\% rrsponden termasuk dalam kategori kadang-kadang berkeikutsertaan pada program posbindu.

Hasil analisis bivariat dilakukan untuk melihat apakah terdapat hubungan antara variabel bebas (pekerjaan, jenis kelamin dan dukungan keluarga) dengan variabel terikat (keikutsertaan lansia). Hasil analisis bivariat dapat dilihat pada tabel berikut ini:

Tabel 2. Hasil Analisis Variabel Pekerjaan, Jenis Kelamin dan Dukungan Keluarga Terhdap Keikutsertaan Lansia Dalam Posbindu

\begin{tabular}{|c|c|c|c|c|c|c|c|}
\hline \multirow{3}{*}{ Variabel } & \multicolumn{4}{|c|}{ Keikutsertaan } & \multirow{2}{*}{\multicolumn{2}{|c|}{ Jumlah }} & \multirow{3}{*}{$P$ value } \\
\hline & \multicolumn{2}{|c|}{ Sering } & \multicolumn{2}{|c|}{$\begin{array}{l}\text { Kadang- } \\
\text { kadang }\end{array}$} & & & \\
\hline & $\mathbf{N}$ & $\%$ & $\mathbf{N}$ & $\%$ & $\mathbf{N}$ & $\%$ & \\
\hline \multicolumn{8}{|l|}{ Pekerjaan } \\
\hline - Bekerja & 7 & 24.1 & 22 & 75.9 & 29 & 100 & 0.011 \\
\hline - Tidak bekerja & 19 & 55.9 & 15 & 44.1 & 34 & 100 & \\
\hline \multicolumn{8}{|l|}{ Pengetahuan } \\
\hline - Baik & 19 & 57,6 & 14 & 42,4 & 33 & 100 & 0,006 \\
\hline - Cukup & 7 & 23,3 & 23 & 76,7 & 30 & 100 & \\
\hline \multicolumn{8}{|l|}{ Jenis kelamin } \\
\hline - Perempuan & 18 & 56.3 & 14 & 43.8 & 32 & 100 & 0.014 \\
\hline - Laki-laki & 8 & 25.8 & 23 & 74.2 & 31 & 100 & \\
\hline \multicolumn{8}{|l|}{ Dukungan } \\
\hline Keluarga & 23 & 54.8 & 19 & 45.2 & 42 & 100 & 2000 \\
\hline - Baik & 3 & 14.3 & 18 & 85.7 & 21 & 100 & 0.002 \\
\hline
\end{tabular}


Berdasarkan pada tabel diatas dapat diketahui bahwa proporsi responden yang sering datang ke posbindu lebih banyak ditemukan pada responden yang tidak bekerja yaitu sebesar 55,9\%. Berjenis kelamin perempuan sebesar 56,3\% dan mendapat dukungan keluarga baik sebesar 54,8\%.

Hasil analisis dengan uji chi-square menujukkan bahwa nilai signifkiansi untuk variabel pekerjaan sebesar 0,011, variabel pengetahuan sebesar 0,006, variabel jenis kelamin sebesar 0,014 dan variabel dukungan keluarga sebesar 0,002. Nilai-nilai tersebut lebih kecil dari nilai 0,05 sehingga dapat diketahui bahwa terdapat hubungan antara variabel pekerjaan dengan keikutsertaan lansia, terdapat hubungan antara variabel pengetahuan dengan keikutsertaan lansia, terdapat hubungan antara variabel jenis kelamin dengan dukungan keluarga, terdapat hubungan antara dukungan keluarga dengan keikutsertaan lansia.

Analisis multivariat menggunakan uji regresi logistik, adapun variabel bebas yang masuk kedalam analisis multivariat adalah varibel yang memiliki nilai p-value $<0,25$ dengan menggunakan metode enter dimana semua variabel bebas dimasukkan kedalam model secara bersamaan. Adapun hasil akhir analisis multivariat adalah sebagai berikut ini:

Tabel 3. Hasil Analisis Multivariat

\begin{tabular}{cccc}
\hline $\begin{array}{c}\text { Variabel } \\
\text { Independen }\end{array}$ & Exp(B) & Sig & $\mathbf{9 5 \% C I}$ \\
\hline Jenis Kelamin & 7,795 & 0,004 & $1,916-31,718$ \\
\hline $\begin{array}{c}\text { Dukungan } \\
\text { Keluarga }\end{array}$ & 5,186 & 0,044 & $1,045-25,725$ \\
\hline
\end{tabular}

Berdasarkan pada tabel diatas dapat diketahui bahwa dari tiga variabel bebas hanya dua variabel yang memiliki nilai signifikansi $<0,05$ yaitu variabel jenis kelamin dan dukungan keluarga. Variabel jenis kelamin diperoleh nilai sig. sebesar $0,004<0,05$ sehingga dapat diketahui variabel jenis kelamin berhubungan dengan keikutsertaan lansia. Besarnya pengaruh ditunjukkan dengan nilai EXP (B) atau disebut juga Odds Ratio (OR). Variabel jenis kelamin dengan OR=7,795 maka orang yang berjenis kelamin laki-laki, mempunyai peluang 7,795 kali lipat kadang-kadang ikutserta di bandingkan dengan jenis kelamin perempuan. Nilai $\mathrm{B}=$ logaritma natural dari 7,795 = 2,053. Oleh karena nilai B bernilai positif, maka jenis kelamin mempunyai hubungan positif dengan keikutsertaan lansia dalam posbindu.

Selain itu, variabel dukungan keluarga memiliki nilai sig $=0,044<0,05$ yang berarti terdapat hubungan antara dukungan keluarga dengan keikutsertaan lansia. Adpaun besarnya pengaruh variabel dukungan keluarga ditunjukkan dengan nilai OR sebesar 5,186. maka orang yang memiliki dukungan keluarga cukup, mempunyai peluang 5,186 kali lipat kadang-kadang ikutserta di bandingkan dengan responden yang mendapat dukungan keluarga Baik. Nilai $\mathrm{B}=$ logaritma natural dari $7,795=2,053$. Oleh karena nilai B bernilai positif, maka jenis kelamin mempunyai hubungan positif dengan keikutsertaan lansia dalam posbindu. 


\section{Pembahasan}

Hasil penelitian menujukkan lansia yang sering ikut serta cenderung lebih banyak ditemukan pada responden yang tidak bekerja. Sedangkan lansia yang kadang-kadang ikut serta lebih banyak ditemukan pada lansia yang bekerja. Hal ini menunjukkan bahwa lansia yang tidak bekerja menujukkan tingkat keikutsertaan yang lebih baik. Hasil uji statistik menujukkan bawa terdapat hubungan antara pekerjaan dengan keikutsertaan lansia dalam kegiatan posbindu $(\mathrm{p}=0,011)$. Hal ini sejalan dengan penelitian yang dilakukan oleh Wahyuni, yang menganalisis keikutsertaan lansia dalam kegiatan pembinaan kesehatan lansia di wilayah kerja Puskesmas Sekar Jaya Kabupaten Ogan Komering Ulu. Dalam penelitiannya menyebutkan bahwa pemanfaatan pelayanan kesehatan dipengaruhi oleh faktor predisposisi yang salah satunya adalah pekerjaan responden. Responden yang bekerja berpeluang 97,154 kali lipat untuk tidak ikut serta dalam kegiatan pembinaan kesehatan dibandingkan dengan responden yang tidak bekerja. ${ }^{11}$

Pengetahuan responden berdasarkan hasil analisis diketahui bahwa lebih dari setengahnya termasuk dalam kategori pengetahuan baik. Proporsi lansia berpengetahuan baik lebih banyak ditemukan pada responden yang sering ikut serta. Sedangkan proporsi lansia dengan pengetahuan cukup lebih banyak ditemukan pada responden dengan keikutsertaan kadang-kadang. Hal ini menunjukkan bahwa tingkat pengetahuan dapat meningkatkan keikutsertaan lansia dalam kegiatan Posbindu. Hasil uji bivariat menujukkan adanya hubungan faktor pengetahuan dengan keikutsertaan lansia dalam kegiatan posbindu. Hal ini sejalan dengan penelitian yang dilakukan oleh Pertiwi, yang menyebutkan bahwa terdapat hubungan antara frekuensi kehadiran lansia di posyandu lansia dengan pengetahuan. ${ }^{12}$ Responden yang memiliki tingkat pendidikan lebih tinggi cenderung lebih aktif berkunjung ke posyandu lansia. Selanjutnya Mengko, menyatakan bahwa tingkat pengetahuan baik yang dimiliki lansia membuat responden lebih aktif dalam memanfaatkan posyandu sebanyak 5,9 kali lebih besar dibandingkan pengetahuan yang kurang baik. ${ }^{13}$

Hasil analisis menujukkan bahwa lebih dari setengahnya $(58,8 \%)$ berjenis kelamin laki-laki. Hasil uji bivariat antara jenis kelamin dan keikutsertaan lansia menujukkan bahwa proporsi lansia yang sering ikut serta dalam posbindu lebih banyak ditemukan pada responden berjenis kelamin perempuan dibandingkan dengan jenis kelamin laki-laki. Sedangkan proporsi lansia yang kadangkadang ikut serta dalam posbindu lebih banyak ditemukan pada responden yang berjenis kelamin laki-laki dibandingkan dengan responden berjenis kelamin perempuan. Hal ini sejalan dengan penelitian yang dilakukan oleh Ningsih dan Arneliwati tentang faktor-faktor yang mempengaruhi minat lansia mengunjungi posyandu lansia. Dalam penelitiannya menyebutkan bahwa lebih dari setengahnya orang yang berkunjung ke posyandu lansia adalah perempuan. ${ }^{14}$

Hasil uji statsitik menujukkan adanya hubungan antara jenis kelamin dengan keikutsertaan lansia dalam posbindu. Hal ini sejalan dengan penelitian yang dilakukan oleh Wahyuni dalam penelitiannya menyebutkan bahwa terdapat hubungan antara jenis kelamin dengan partisipasi lansia dalam kegiatan pembinaan kesehatan lansia. Kaum perempuan cenderung lebih peka terhadap kondisi kesehatannya dan lebih rentan terhadap penyakit. Kondisi demikian yang menyebabkan lansia perempuan lebih aktif berkunjung ke kegiatan pembinaan lansia karena mereka berharap agar konsisi kesehatannya tetap baik. ${ }^{11}$

Hasil analisis menujukkan bahwa lebih dari setengahnya dukungan keluarga lansia termasuk dalam kategori baik. Hasil analisis bivariat menujukkan bahwa proporsi responden yang sering datang ke posbindu lebih banyak ditemukan pada responden yang mendapatkan dukungan keluarga baik dibandingkan dengan yang mendapatkan dukungan keluarga cukup. Sedangkan proporsi keikutsertaan responden yang termasuk dalam kategori kadang-kadang lebih banyak ditemukan 
pada responden dengan dukungan keluarga cukup. hal ini menunjukkan bahwa dukungan keluarga yang baik dapat meningkatkan keikutsertaan lansia dalam posbindu.

Hasil uji statistik menujukkan bahwa terdapat hubungan antara dukungan keluarga dengan keikutsertaan lansia dalam posbindu. Hal ini sejalan dengan penelitian yang dilakukan oleh Purdiyani yang menyebutkan bahwa pengaruh peran keluarga sangat diperlukan agar lansia mau berkeikutsertaan dalam pemanfaatan posbindu. Harapan anggota keluarga terhadap kondisi kesehatan lansia merupakan dasar terwujudnya dukungan keluarga agar lansia mau memanfaatkan posbindu. ${ }^{15}$ Selanjutnya Wahyuni mengatakan bahwa, bentuk-bentuk dukungan keluarga dapat berupa pemberian motivasi, menyediakan diri untuk mendampingi lansia ke posyandu dan mengingatkan jadwal posyandu lansia. ${ }^{11}$

Berdasarkan hasil analisis multivariat diketahui bahwa jenis kelamin merupakan faktor yang berpengaruh terhadap keikutsertaan lansia dalam kegiatan posbindu. Dengan nilai Exp(B) sebesar 7,795 yang artinya orang yang berjenis kelamin laki-laki, mempunyai peluang 7,795 kali lipat kadang-kadang ikut serta di bandingkan dengan jenis kelamin perempuan. Penelitian ini sejalan dengan penelitian yang dilakukan oleh Rusdiyanti tentang faktor-faktor yang mempengaruhi keaktifan kunjungan pos pembinaan terpadu penyakit tidak menular di desa. Hasil penelitiannya menyebutkan bahwa lebih banyak responden perempuan yang berkunjung ke posbindu dibandingkan dengan laki -laki. Analisis lebih lanjut menujukkan adanya hubungan yang bermakna antara jenis kelamin dengan keaktifan kunjungan posbindu PTM. ${ }^{16}$ Hal ini berarti juga bahwa jenis kelamin seseorang mempunyai korelasi dengan keaktifan kunjungan posbindu PTM. Selain itu lansia berjenis kelamin perempuan memiliki kesadaran yang lebih tinggi dibandingkan dengan lansia laki-laki, hal ini disebabkan pengalaman yang dimilikinya ketika menjadi seorang ibu ketika membawa anak-anaknya ke posynadu, ibu-ibu lebih merasakan manfaat yang diperoleh ketika datang ke posyandu dari pada laki-laki. ${ }^{17}$

\section{Kesimpulan}

Berdasarkan penelitian yang telah dilakukan dapat disimpulkan bahwa proporsi responden yang sering datang ke posbindu lebih banyak ditemukan pada responden yang tidak bekerja, lebih dari setengahnya berjenis kelamin perempuan dan lebih dari setengahnya mendapat dukungan baik dari keluarganya. Hasil analisis bivariat menujukkan variabel yang berhubungan dengan keikutsertaan lansia dalam posbindu yaitu pekerjaan, pengetahuan, jenis kelamin dan dukungan keluarga. Hasil analisis multivariat menujukkan variabel yang paling berpengaruh terhadap keikutsertaan lansia adalah jenis kelamin.

\section{Saran}

Faktor yang paling berpengaruh terhadap keikutsertaan lansia dalam kegiatan posbindu adalah jenis kelamin. Oleh karena itu keluarga atapun masyarakat dan kader kesehatan dapat lebih memotivasi lansia untuk berkunjung ke Posbindu khususnya lansia yang berjenis kelamin laki-laki.

\section{Ucapan Terima Kasih}

Kementerian Riset, Pendididikan dan Teknologi Pendidikan Tinggi Republik Indonesia, LPPM Universitas Siliwangi, STIKes Kuningan, Dinas Kesehatan Kabupaten Kuningan, dan Puskesmas Nusaherang Kabupaten Kuningan 


\section{Daftar Pustaka}

1. Pusdatin. 2012. Penyakit Tidak Menular. Jakarta: Pusat Data dan Informasi - Kementerian Kesehatan Republik Indonesia.

2. BPS. 2016. Survei Sosial Ekonomi Nasional 2016 Maret (KOR). Jakarta: Badan Pusat Statistik. Available: https://microdata.bps.go.id/mikrodata/index.php/catalog/769 [Accessed 02/08 2019].

3. Kemenkes RI. 2017. Analisis Lansia di Indonesia. Jakarta: Pusat Data dan Informasi Kementerian Kesehatan Republik Indonesia.

4. Kemenkes RI. 2013. Riset Kesehatan Dasar 2013, Jakarta:Kementerian Kesehatan Republik Indonesia.

5. Dinas Kesehatan Provinsi Jawa Barat. 2016 Laporan Kinerja Instansi Pemerintah (LKIP) 2016. Bandung: Dinas Kesehatan Provinsi Jawa barat.

6. Rahajeng, E. \& Tuminah, S. 2009. Prevalensi hipertensi dan determinannya di Indonesia. Majalah Kedokteran Indonesia, 59(12): 580-587.

7. Anggara, F. H. D. \& Prayitno, N. 2013. Faktor-faktor yang berhubungan dengan tekanan darah di Puskesmas Telaga Murni, Cikarang Barat tahun 2012. Jurnal ilmiah kesehatan, 5(1): 20-25.

8. Kemenkes RI. 2014. Pedoman Umum Pos Pembinaan Terpadu Penyakit Tidak Menular. Jakarta: Kementerian Kesehatan RI.

9. Manihuruk, M. 2018. Faktor-faktor yang Berhubungan dengan Kunjungan Lansia ke Posbindu Lansia di Wilayah Kerja Puskesmas Kelurahan Bintara Kota Bekasi Tahun 2017. Jurnal Kebijakan Kesehatan Indonesia: JKKI, 7(4): 158-167.

10. Try U, H. \& Hary C, W. 2015. Dukungan Keluarga dan Tokoh Masyarakat Terhadap Keaktifan Penduduk ke Posbindu Penyakit Tidak Menular. Junal Kesehatan Masyarakat, 11(1): 96-101

11. Wahyuni, I. D. W. D., Ainy, A. \& Rahmiwati, A. 2016. Analisis Partisipasi Lansia Dalam Kegiatan Pembinaan Kesehatan Lansia Di Wilayah Kerja Puskesmas Sekar Jaya Kabupaten Ogan Komering Ulu. Jurnal Ilmu Kesehatan Masyarakat, 7(2): 96-107.

12. Pertiwi, H. W. 2013. Faktor-faktor Yang Berhubungan Dengan Frekuensi Kehadiran Lanjut Usia Di Posyandu Lansia. Bidan Prada: Jurnal Publikasi Kebidanan Akbid YLPP Purwokerto, 4(01): $1-15$.

13. Mengko, V. V. 2015. Pemanfaatan Posyandu Lansia di Wilayah Kerja Puskesmas Teling Atas Kota Manado. JIKMU, 5(5): 479-490.

14. Ningsih, R. \& Arneliwati, W. L. 2014. Faktor-faktor yang Mempengaruhi Minat Lansia Mengunjungi Posyandu Lansia. JOM, 1(2): 1-9.

15. Purdiyani, F. 2016. Pemanfaatan Pos Pembinaan Terpadu Penyakit Tidak Menular (POSBINDU PTM) Oleh Wanita Lansia Dalam Rangka Mencegah Penyakit Tidak Menular di Wilayah Kerja Puskesmas Cilongok 1. Jurnal Kesehatan Masyarakat (e-Journal), 4(1): 470-480.

16. Rusdiyanti, I. 2018. Faktor-Faktor Yang Mempengaruhi Keaktifan Kunjungan Pos Pembinaan Terpadu Penyakit Tidak Menular Di Desa. Healthy-Mu Journal, 1(2): 51-58.

17. Amaral, A., Wiyono, J. \& Candrawati, E. 2017. Analisis Faktor Kehadiran Lansia Dalam Mengikuti Posyandu Di Desa Pagersari Kecamatan Ngantang Kabupaten Malang. Nursing News: Jurnal Ilmiah Keperawatan, 2(2): 739-748. 